\title{
NOBLE METAL INJECTION DURING POWER OPERATION FOR BWR CRACK MITIGATION AND DOSE RATE REDUCTION
}

\author{
S. Hettiarachchi \\ GE Energy, Vallecitos Nuclear Center \\ 6705, Vallecitos Road \\ Sunol, CA 94586, USA \\ samson.hettiarachchi@gene.ge.com
}

\author{
T. P. Diaz \\ GE Energy, Vallecitos Nuclear Center \\ 6705, Vallecitos Road \\ Sunol, CA 94586, USA \\ thomas.diaz@gene.ge.com
}

Keywords : NobleChem ${ }^{\mathrm{TM}}$, BWR Crack Mitigation, Dose Rate Reduction, ECP, MSLRM

\section{INTRODUCTION}

NobleChem ${ }^{\mathrm{TM}}$ is a technology that has been accepted by the Boiling Water Reactor (BWR) industry as a means to lower ECP with low hydrogen addition, thus satisfying the criteria needed for stress corrosion cracking (SCC) mitigation. Currently, 31 operating BWRs have applied NobleChem ${ }^{\mathrm{TM}}$ and the total cumulative NobleChem ${ }^{\mathrm{TM}}$ experience is about 180 reactor operating years.

Recently, GE developed and implemented a more effective new generation On-Line NobleChem ${ }^{\mathrm{TM}}$ application (OLNC) that can be employed while the BWR is operating at full power, and hence eliminates the costly critical path time requirement. Furthermore, the OLNC application is not outage related, is transparent to plant operations, and requires the use of platinum chemical only.

OLNC applications were performed three times in a European BWR 4, and once in a US BWR/2. The applications were successfully completed with no increase in operating dose rates, no impact on plant operations and no unexpected changes to water chemistry parameters. This paper presents the encouraging ECP results (Figure 1), drywell dose rate results and the shroud ultrasonic (UT) crack growth rate observations following OLNC application.

\section{ADVANTAGES OF OLNC}

The advantages of OLNC are that cracks experience their normal residual stresses corresponding to plant operating conditions, and the cracks remain potentially more open during application, thus allowing enhanced penetration of $\mathrm{Pt}$ catalyst into the cracks so that noble metal can deposit inside the crack mouth more readily.



Figure 1. US BWR/2 Recirculation Piping ECP Response During OLNC 


\section{NOBLE METAL INJECTION DURING POWER OPERATION FOR BWR CRACK MITIGATION AND DOSE RATE REDUCTION}

\author{
S. Hettiarachchi \\ GE Energy, Vallecitos Nuclear Center \\ 6705, Vallecitos Road \\ Sunol, CA 94586, USA \\ samson.hettiarachchi@gene.ge.com
}

\author{
T. P. Diaz \\ GE Energy, Vallecitos Nuclear Center \\ 6705, Vallecitos Road \\ Sunol, CA 94586, USA \\ thomas.diaz@gene.ge.com
}

Keywords : NobleChem ${ }^{\mathrm{TM}}$, BWR Crack Mitigation, Dose Rate Reduction, ECP, MSLRM

\begin{abstract}
NobleChem ${ }^{\mathrm{TM}}$ is a technology that has been accepted by the Boiling Water Reactor (BWR) industry as a means to lower ECP with low hydrogen addition, thus satisfying the criteria needed for stress corrosion cracking (SCC) mitigation. Currently, 31 operating BWRs have applied NobleChem ${ }^{\mathrm{TM}}$ and the total cumulative NobleChem ${ }^{\mathrm{TM}}$ experience is about 180 reactor operating years. The conventional NobleChem ${ }^{\mathrm{TM}}$ technology requires the injection of a mixture of platinum and rhodium chemicals into the reactor at a lower temperature of 115 to $143^{\circ} \mathrm{C}$, and takes about 60 hours of critical path time.
\end{abstract}

Recently, GE developed and implemented a more effective new generation On-Line NobleChem ${ }^{\mathrm{TM}}$ application (OLNC) that can be employed while the BWR is operating at full power, and hence eliminates the costly critical path time requirement. Furthermore, the OLNC application is not outage related, is transparent to plant operations, and requires the use of platinum chemical only.
The first OLNC application was completed in a European BWR in July 2005 followed by a second OLNC application in the same plant in January 2006. The application was successfully completed with no increase in operating dose rates, no impact on plant operations and no unexpected changes to water chemistry parameters. This paper presents the application results, the encouraging drywell dose rate results and the shroud ultrasonic (UT) crack growth rate observations following OLNC application.

\section{INTRODUCTION}

The core of a BWR generates numerous radiolytic species due to the interaction of water with neutron and gamma radiation that can be represented by more than 30 reactions. The species generated are a mixture of oxidants and reductants that have extremely short to long half-lives and varying degrees of oxidizing potentials. The most oxidizing and most damaging species such as hydroxyl radicals have short half-lives and play a minor role in the overall corrosion process. Despite the large 
number of species generated, the most stable species in the $\mathrm{BWR}$ environment include $\mathrm{H}_{2}, \mathrm{O}_{2}$ and $\mathrm{H}_{2} \mathrm{O}_{2}$ [1]. Because of the relatively low volatility of $\mathrm{H}_{2} \mathrm{O}_{2}$, $B W R$ water in its natural environment remains largely oxidizing which produces internal component ECPs in the range of +100 to $+300 \mathrm{mV}$ (SHE) [2]. The ECPs in the lower range are due to measurement aberrations associated with the non-representative nature (sample line effects) of the measurement location [1], that has less oxidants (e.g. $\mathrm{H}_{2} \mathrm{O}_{2}$ ) than the single phase regions of the reactor pressure vessel. Recent findings have clearly demonstrated that outside of the incore regions (upper and lower core) and the upper downcomer region, the most oxidizing region of the BWR is the lower plenum in jet pump BWRs [3]. Because different regions of the BWR are oxidizing to different extents, they do require different levels of feedwater hydrogen concentrations to reach the hydrogen water chemistry (HWC) mitigation specification potential of $<-230 \mathrm{mV}$ (SHE). The lower plenum requires more hydrogen than the recirculation piping to reach an ECP of $<-230 \mathrm{mV}$ (SHE).

However, with the advent of NobleChem $^{\text {TM }}$ technology [4-7], all BWR locations with excess $\mathrm{H}_{2}$ are able to reach low ECPs $[<-450 \mathrm{mV}(\mathrm{SHE})]$ with low feedwater $\mathrm{H}_{2}$ concentration ( 0.15 to $0.4 \mathrm{ppm}$ ), as shown in Figure 1. The principle governing this observation reflects the unique characteristics of noble metal catalysts or noble metal treated surfaces. At BWR operating temperatures of $288^{\circ} \mathrm{C}$, the oxidants and hydrogen undergo rapid catalytic reaction generating water, thus reducing the oxidant concentration as long as there is a molar excess of $\mathrm{H}_{2}$ in the single phase water, i.e. $\mathrm{H}_{2} / \mathrm{O}_{2}$ molar ratio of $>$ 2. Figure 1 shows that after
NobleChem ${ }^{\mathrm{TM}}$, not only do the ECPs decrease to low values with very low $\mathrm{H}_{2}$ addition, but also that the low ECPs are independent of the measurement location. This is a significant advantage over conventional HWC which require different levels of $\mathrm{H}_{2}$ addition to reach low ECPs at different locations. Based on numerous laboratory crack growth studies conducted by many investigators $[6,8$ $10]$, there is convincing evidence that low ECPs result in low crack growth rates [10]. This was also confirmed by plant shroud crack lengthening ultrasonic (UT) data from a NobleChem ${ }^{\mathrm{TM}}$ plant that showed the expected SCC mitigation benefit following NobleChem ${ }^{\mathrm{TM}}$ and low hydrogen addition [11]. However, UT examination of shroud cracks of another BWR that had applied NobleChem ${ }^{\mathrm{TM}}$ and exhibited low ECP $[<-450 \mathrm{mV}(\mathrm{SHE})]$ showed that some of the actively growing shroud ID cracks continued to grow in the length direction despite low ECP. The plant had a nine-week period of delay before initiating $\mathrm{H}_{2}$ addition following plant start-up. It is postulated that this is due to a process called "crack flanking" that potentially occurred during the hydrogen off period [12]. The postulation here is that during the $\mathrm{H}_{2}$ off period, shroud cracks continued to lengthen because of the high potential conditions at the crack mouth, and if sufficient time elapsed, they would grow to a length where new growth areas have no noble metal. Thus, even if low $\mathrm{H}_{2}$ is introduced after some period of time, the new growth areas inside the crack mouth would continue to have high potential due to lack of noble metal and would continue to grow at the NWC growth rate. Thus, faster growing cracks are more prone to encounter this situation early, and will not benefit from 
NobleChem ${ }^{\mathrm{TM}} /$ low $\mathrm{H}_{2}$, if $\mathrm{H}_{2}$ is interrupted over an extended period of time. Clearly, hydrogen availability is a crucial factor in continued attempts to mitigate SCC of power plant internal components.

In order to circumvent crack flanking, a process is required that can inject noble metal periodically in to the BWR water so that noble metal can be deposited on the newly generated flanked crack surfaces while the plant is in power operation. This paper describes the On-Line NobleChem ${ }^{\text {TM }}$ (OLNC) application benefits in the same overseas BWR/4 that showed both shutdown dose rate reduction and preliminary indications of crack growth rate reduction. The OLNC process was applied while the plant was at power operating conditions, and required no critical path outage time for its implementation. More recently, a US BWR/2 also applied OLNC successfully, with no impact on plant operations. This BWR also showed isotopic release during OLNC application indicating that there is a potential likelihood of shutdown dose rate reduction, provided there is no excessive recontamination of piping surfaces during the period between the OLNC application and the refueling outage.

\section{ADVANTAGES OF OLNC}

The advantages of OLNC are that cracks experience their normal residual stresses corresponding to plant operating conditions, and the cracks remain potentially more open during application, thus allowing enhanced penetration of $\mathrm{Pt}$ catalyst in to the cracks so that the noble metal can deposit inside the crack mouth more readily. Furthermore, since the plant is expected to operate at $>75 \%$ power and $>85 \%$ core flow during OLNC, the cracks are subjected to maximum flow velocities experienced by crack openings allowing convective transport of noble metal particles in to the cracks by eddy diffusion in addition to other transport modes. Thus, with OLNC, there is a greater probability of getting noble metal inside the crack mouth compared to the conventional NobleChem $^{\mathrm{TM}}$ process where the application temperatures are lower, coolant flow is lower and the cracks are in a more unloaded and a potentially more closed condition during the application.

A variety of laboratory and plant tests were conducted to prove that OLNC, 1) provides low ECPs of noble metal treated surfaces with low $\mathrm{H}_{2}$ injection, 2) allows sufficient noble metal penetration into cracks/crevices with a relatively uniform distribution, 3) mitigates crack flanking under excess $\mathrm{H}_{2}$ conditions, 4) does not cause any undesirable water chemistry transients that affect plant operation including undesirable N-16 increases during application, and 5) has no impact on fuel performance based on extensive post-NobleChem ${ }^{\mathrm{TM}}$ fuel surveillance data available. Details of these activities are described elsewhere $[12,13]$.

\section{ON-LINE NOBLECHEM ${ }^{\mathrm{TM}}$ PLANT APPLICATION MONITORING}

Despite the encouraging laboratory and plant data, a potential Main Steam Line Radiation (MSLR) and fence dose rate increase were still a concern. Therefore, preliminary short-term platinum injections, beginning from very low injection rates to incrementally higher levels, were 
performed prior to the continuous injection period. It was thought that catalytic Pt would enhance generation of volatile $\mathrm{N}^{16}$ containing species that would be carried over into the steam phase and would result in MSLR increases. The operating dose rate increases were expected to be temporary and were expected to subside following cessation of noble metal injection, if such an increase were to occur. Another concern was the potential impact of OLNC on reactor water chemistry and plant operating parameters. Therefore, these were also closely monitored during the $\mathrm{Pt}$ injection step tests.

Since the noble metal injection rates were low, the reactor water platinum concentration during the step tests and continuous injection period were low, the maximum observed being $43 \mathrm{ppt} \mathrm{Pt}$ over a period of several hours. The chemistry parameters monitored and the contingency plans that were in place during the application period appear elsewhere [12].

No MSLR or fence dose rate increases attributable to $\mathrm{Pt}$ injection were observed at this $\mathrm{BWR} / 4$, even at the highest $\mathrm{Pt}$ injection rate used at $100 \%$ power.

\section{OLNC APPLICATION EXPERIENCE IN A EUROPEAN BWR/4}

OLNC application was performed in the overseas BWR/4 in June/July 2005 , followed by a second application in January 2006. It included a stepwise $\mathrm{Pt}$ injection rate increase test period to determine any $\mathrm{N}^{16}$ impacts due to $\mathrm{Pt}$ injection, followed by a continuous $\mathrm{Pt}$ injection period lasting about 8 days to get sufficient $\mathrm{Pt}$ inside the crack mouth. Both applications were successfully concluded with no impact on MSLRM or fence dose rates, and no impact on plant operations.

The reactor water temperature during OLNC was $281^{\circ} \mathrm{C}$, compared to the temperature of 115 to $143^{\circ} \mathrm{C}$ used in conventional NobleChem ${ }^{\mathrm{TM}}$ applications. The plant power during OLNC was $>75 \%$, and the core flow was maintained at $>85 \%$ to ensure typical reactor water flow velocities past any existing cracks. During OLNC, a predetermined quantity of a platinum compound, sodium hexahydroxy platinate $\left[\mathrm{Na}_{2} \mathrm{Pt}(\mathrm{OH})_{6}\right]$ in solution form was injected into the reactor feedwater system to carry platinum into all wetted regions of the reactor. With OLNC, it is expected that platinum deposits deeper in the crack mouth since the cracks potentially remain more open. The deposition of platinum on reactor interior surfaces, including inside of existing cracks and flanked cracks, is expected to lower the electrochemical corrosion potential $(\mathrm{ECP})$ to $<-230$ $\mathrm{mV}$ (SHE) in the presence of excess hydrogen. The lowering of ECP is expected to significantly reduce the crack growth rates based on numerous laboratory and plant crack growth rate data. Furthermore, lower ECP is expected to mitigate crack initiation as well.

During the first OLNC application there were some variations in plant power, however, during the second OLNC application, the plant power remained constant at $100 \%$. No increases in MSLR or fence dose rates were observed during both applications. 


\section{RESULTS AND DISCUSSION}

\subsection{Reactor Water Chemistry and MSLR}

Figures 2 and 3 show the reactor water sodium and reactor water $\mathrm{Pt}$ build-up during the second OLNC application, where the total Pt input was about 98 grams. As expected, the reactor water sodium reached a steady state value relatively quickly whereas it took about 4 days for the reactor water Pt to reach a steady state value of about $20 \mathrm{ppt}$, before it started increasing to a maximum value of 43 ppt. The slow increase in reactor water $\mathrm{Pt}$ and the low concentrations observed are attributed to the rapid deposition of $\mathrm{Pt}$ on plant internals surfaces.

Figure 4 shows that the $\mathrm{Pt}$ concentration in reactor water increased from zero to about $43 \mathrm{ppt}$ while showing a slight decrease in MSLR at these concentrations. Therefore, it is concluded that Pt at these concentrations in the reactor water has no negative impact on MSLR or fence dose rates during the OLNC application.

\subsection{Reactor Water Isotopics and Dose Rate Reduction}

An important feature of OLNC applications is the release of isotopics as a result of the oxide restructuring process. The release of isotopics occur because as Pt is being injected, more areas of the hematite containing surface oxide undergoes reduction to magnetite. This process releases soluble iron in to the reactor water, which in turn releases isotopics contained in the oxide/crud layer. The common isotopics released are $\mathrm{Cr}-51$, $\mathrm{Fe}-59, \mathrm{Mn}-54, \mathrm{Co}-60$ and Co-58. While a majority of the isotopics come from fuel crud, some isotopics will have to come from piping surfaces as well. Figure 5 is an illustration of the increased isotopic concentration during the OLNC application. If some of the isotopics are released from piping surfaces, a reduction in shut down dose rate was expected at the next outage. Figure 6 is a confirmation of this expectation following the OLNC application. After the first OLNC application with an input of $37 \mathrm{~g}$ of $\mathrm{Pt}$, the dose rate at the outage decreased by about $10 \%$, measured one month following the OLNC application. After the second OLNC application with a Pt input of $99 \mathrm{~g}$, the outage dose rate decreased by another $18 \%$. The latter decrease occurred despite the fact that there was a 7-month potential recontamination period between the OLNC application and the outage. Therefore, there is consistent data supporting that OLNC leads to a "soft decontamination" of the piping resulting in lower shutdown dose rates.

\subsection{Crack Growth Reduction} Following OLNC

Following the second OLNC application, ultrasonic (UT) crack length measurements of two of the fast growing indications at mid-shroud elevations were made. Both cracks showed a reduction in growth rate. While this is a very encouraging result, more data are needed to confirm this significant benefit of OLNC technology. If further confirmed, OLNC can be used to effectively mitigate growing cracks during plant operation, if and when hydrogen interruptions do occur.

\subsection{First OLNC Application in a US $\underline{\text { BWR }}$}

Following the successes of OLNC applications in the overseas BWR/4, the first OLNC application in the US 
was performed in a $B W R / 2$ in December 2006. The application was performed about 3 months before the refueling outage with the plant at $100 \%$ power. The application period was about 11 days with a total Pt input of 486 grams. The plant historically had high feedwater iron levels, and recently installed iron prefilters. However, since the old fuel still has considerable crud levels, it was expected that the build-up of $\mathrm{Pt}$ in reactor water would be slower. Figure 7 shows reactor water $\mathrm{Pt}$ build-up during the OLNC application. Clearly, the reactor water $\mathrm{Pt}$ concentration varies considerably due to the presence of crud in reactor water. The highest $\mathrm{Pt}$ concentration observed was $39 \mathrm{ppt}$, the same water sample when digested with aqua regia showed the $\mathrm{Pt}$ concentration to be around $115 \mathrm{ppt}$ indicating that there is a considerable amount of $\mathrm{Pt}$ in the reactor water that is presumably attached to crud.

A significant finding during the US BWR/2 OLNC application was the rapidity with which the ECP decreased with time of $\mathrm{Pt}$ injection. Figure 8 shows that the recirculation piping ECP decreased from $-50 \mathrm{mV}$ (SHE) before Pt injection to less than -230 $\mathrm{mV}$ (SHE) within 5 hours, and to less than $-400 \mathrm{mV}$ (SHE) within 13 hours. The extremely rapid ECP response observed indicates that $\mathrm{Pt}$ is depositing rapidly and efficiently on recirculation piping surfaces and remains quite catalytic. The ECP reached values as low as $-480 \mathrm{mV}(\mathrm{SHE})$ during injection and remained at this value even after the $\mathrm{Pt}$ injection was stopped, confirming that the ECP decrease is related to deposition of $\mathrm{Pt}$ on surfaces and is not related to the presence of $\mathrm{Pt}$ in the water.

\section{CONCLUSIONS}

The first and second On-line NobleChem $^{\mathrm{TM}}$ applications in an operating BWR/4 were successfully completed during the period June/July 2005 and January 2006, with no impact on any of the plant operating parameters.

The injection of $\mathrm{Pt}$ in to the BWR, while it was operating at $100 \%$ power, showed no increase in the main steam line radiation monitor readings or the fence dose rates.

The impact of $\mathrm{Pt}$ injection on reactor water chemistry was less than expected.

The maximum reactor water platinum measured was 43 ppt during the second OLNC application. This value is lower than expected because of $\mathrm{Pt}$ deposition on internals, and perhaps in the sample line.

It was confirmed that OLNC application triggers isotopic releases with a resulting decrease in outage dose rates, thus constituting a "soft decontamination" of the piping surfaces.

The preliminary data from the BWR/4 also showed encouraging crack mitigation benefit that needs to be further confirmed during future shroud inspections.

It is anticipated that a higher $\mathrm{Pt}$ amount will be injected at the next application, in order to achieve higher reactor water $\mathrm{Pt}$ concentrations and achieve low ECPs for on-line crack mitigation.

The OLNC data obtained from the first US BWR application was also 
very encouraging that resulted in low ECPs within 13 hours of the application, confirming that with OLNC, SCC mitigation criteria can be achieved within a short period of time.

\section{REFERENCES}

1. Rooth, T, Ullberg, M, Karlsson, E, Persson, I., Proc. Int. Conf. Water Chemistry of Nuclear Reactor Systems 5, Vol 2, p.55, BNES, London (1989).

2. Cowan, R.L, Hettiarachchi,S, Hale, D.A, Law, R.J., Proc. Water Chemistrty'98, JAIF, p.419, Oct 13-16, Kashiwazaki, Japan, 1998.

3. Hettiarachchi, S, Hale, D.A, Burrill, R, Gorrochategui, I, Coello, R, Suzuki, S, Sambongi, M, Proc. $9^{\text {th }}$ Int Symp. On Env. Degradation of Materials in Nuclear Power Systems-Water Reactors, NACE International, August 15, Newport Beach, California, 1999.

4. Hettiarachchi, S, Wozadlo, G.P, Diaz, T.P., Paper\#95413, CORROSION/1995.

5. Hettiarachchi, S, Wozadlo, G.P, Andresen, P.L, Diaz, T.P, Cowan, R.L, Proc. $7^{\text {th }}$ Int Symp. On Env. Degradation of Materials in Nuclear Power Systems-Water Reactors, NACE International, August 710, Breckenridge, Colorado, 1995.

6. Cowan, R.L., Proc. Int. Conf. Water Chemistry of Nuclear Reactor Systems 7, Bournemouth, October 13-17, BNES, London (1996).

7. Hettiarachchi, S., Proc. $10^{\text {th }}$ Int Symp. On Env. Degradation of Materials in Nuclear Power Systems-Water Reactors,
NACE International, August 59, Lake Tahoe, Nevada, 2001.

8. Indig, M.E, McIlree, A.R, Corrosion, 38, 288 (1979).

9. Andresen, P.L, Ford, F.P., Mat. Sci. Eng., A 103, 167 (1988).

10. Andresen, P.L, Diaz, T.P, Hettiarachchi, S., Paper\# 04668, CORROSION/2004.

11. Hettiarachchi, S and Diaz, T.P., Int. Conference on Water Chemistry of Nuclear Reactor Systems, Oct 11-14, Jeju Island, Korea, 2006.

12. Hettiarachchi, S., Int. Conference on Water Chemistry of Nuclear Reactor Systems, Oct 11-14, San Francisco, California, 2004.

13. Hettiarachchi, S., Proc. $12^{\text {th }}$ Int Symp. On Env. Degradation of Materials in Nuclear Power Systems-Water Reactors, NACE International, August 15-18, Snowbird Resort, Utah, 2005 .

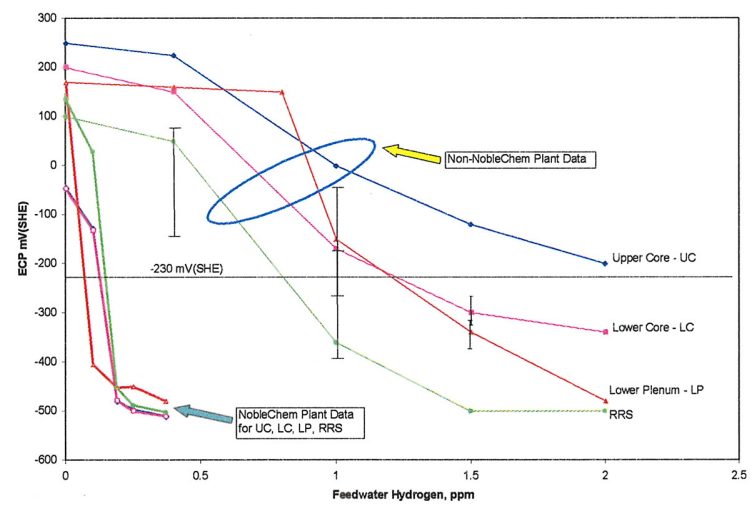

Figure 1. NobleChem ${ }^{\mathrm{TM}}$ and nonNobleChem ${ }^{\mathrm{TM}}$ BWR ECP Data for Different In-Vessel Locations. 


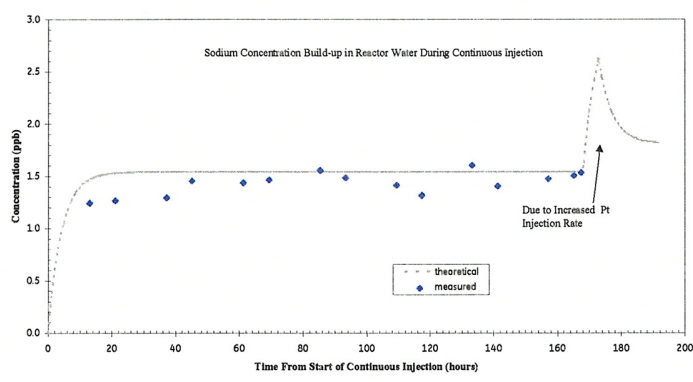

Figure 2. Build-up of Reactor Water Sodium Ion Concentration With Chemical Injection Time.

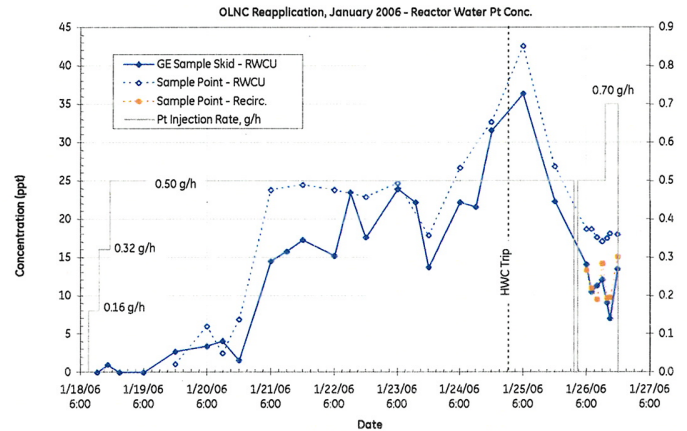

Figure 3. Platinum Concentration Variation During the Second OLNC Application.



Figure 4. MSLR Monitor Response to Reactor Water Pt Concentration.

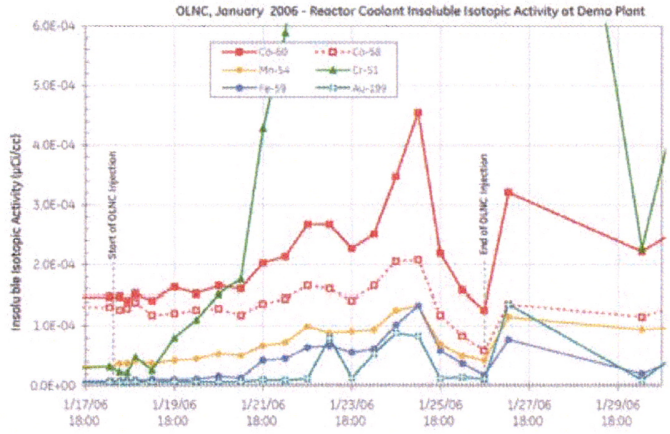

Figure 5. Reactor Water Isotopic Release During Pt Injection.

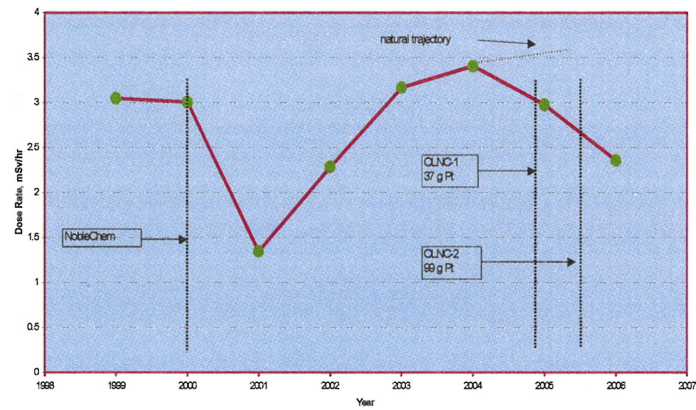

Figure 6. Outage Dose Rate Reduction Following OLNC Application.



Figure 7. Reactor Water Pt Concentration Variation During OLNC at US BWR/2. 


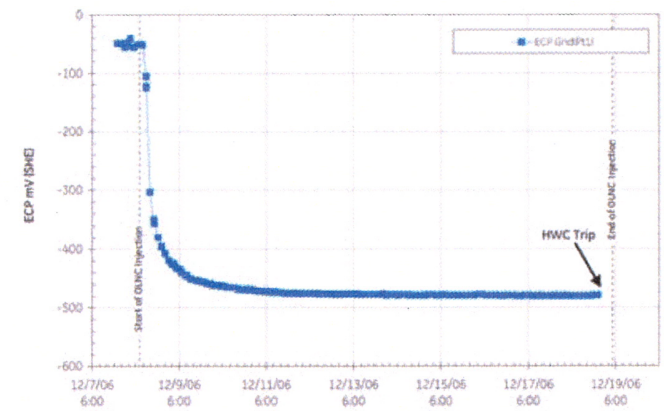

Figure 8. US BWR/2 Recirculation Piping ECP Response During OLNC. 